\title{
Relationship between Microscopic Hematuria and Inferior Vena Cava Reflux on Color Doppler Ultrasonography*
}

\author{
Kimio Sugaya $^{1,2 \#}$, Saori Nishijima ${ }^{2}$, Katsumi Kadekawa ${ }^{2,3}$, Katsuhiro Ashitomi ${ }^{2}$ \\ ${ }^{1}$ Department of Urology, Kitakami Central Hospital, Okinawa, Japan \\ ${ }^{2}$ Southern Knights' Laboratory LLP, Okinawa, Japan \\ ${ }^{3}$ Department of Urology, Okinawa Kyodo Hospital, Okinawa, Japan \\ Email: "sugaya@sklabo.com
}

Received November 4, 2013; revised November 27, 2013; accepted December 3, 2013

Copyright (C) 2013 Kimio Sugaya et al. This is an open access article distributed under the Creative Commons Attribution License, which permits unrestricted use, distribution, and reproduction in any medium, provided the original work is properly cited. In accordance of the Creative Commons Attribution License all Copyrights (C) 2013 are reserved for SCIRP and the owner of the intellectual property Kimio Sugaya et al. All Copyright (C) 2013 are guarded by law and by SCIRP as a guardian.

\begin{abstract}
We examined the relationship between microscopic hematuria and inferior vena cava (IVC) reflux. Transabdominal color Doppler ultrasonography of the IVC was performed in the supine position with the convex probe positioned perpendicular to the upper abdominal wall, and the extent of reflux into the IVC with each heart beat was examined near the diaphragm. A total of 171 patients were studied who had no diseases that could cause hematuria, and no symptomatic gross hematuria. The relationship between the existence and severity of IVC reflux and urine occult blood was examined. The 98 males included 50 subjects without IVC reflux and 48 with reflux, while the 73 females included 24 without IVC reflux and 49 with IVC reflux, respectively. The occurrence of IVC reflux was unrelated to age, but the prevalence of reflux was significantly higher in females than males. As the grade of IVC reflux increased, there was an increase in the prevalence and the severity of hematuria in both males and females. In conclusion, IVC reflux could be related to the occurrence of microscopic hematuria. Renal or urinary tract congestion secondary to IVC reflux may be one of the factors contributing to hematuria.
\end{abstract}

Keywords: Inferior Vena Cava Reflux; Ultrasonography; Hematuria

\section{Introduction}

The nutcracker phenomenon of the left renal vein involves compression of this vein between the abdominal aorta and the superior mesenteric artery [1], resulting in varicocele, left renal congestion with hematuria [2], and pain and dysfunction of the pelvic organs [3]. Unilateral or bilateral ovarian vein incompetence can cause the pelvic congestion syndrome or lead to vulval varices and varicose veins in the lower limbs [4-7]. We previously reported a female patient who had pelvic congestion syndrome due to inferior vena cava (IVC) reflux associated with tricuspid regurgitation [8]. After that, we identified many other patients who had IVC reflux on color Doppler ultrasonography. IVC reflux may originate from tricuspid regurgitation, which has a very high prevalence of $70 \%$ among adults in Japan [9], or $17 \%$ - $68 \%$ in patients with otherwise "normal" hearts from the USA

\footnotetext{
${ }^{*}$ Conflict of interest: None declared.
}

${ }^{*}$ Corresponding author.
[10,11]. To examine the severity of tricuspid regurgitation, echocardiography is usually performed, but this examination is not readily available for urologists. However, urologists can easily evaluate IVC reflux by performing color Doppler ultrasonography. We previously examined the relationship between urological disease and IVC reflux, revealing that chronic prostatitis in males and stress incontinence in females are significantly associated with reflux [12]. Since pelvic congestion due to IVC reflux is associated with chronic prostatitis and stress incontinence, IVC reflux may also be related to renal congestion, which is one of the causes of hematuria. Therefore, we investigated whether there was a relationship between asymptomatic hematuria and the detection of IVC reflux on color Doppler ultrasonography.

\section{Materials and Methods}

Transabdominal color Doppler ultrasonography of the IVC was performed in patients attending the urological 
outpatient clinics of Ryukyu University Hospital, Kitakami Central Hospital, and Okinawa Kyodo Hospital between January 2008 and December 2011. The ultrasound unit was a GE Medical Voluson 730 Expert. We explained the purpose of this study to each patient, and obtained consent. Each patient was placed in the supine position and the convex probe was positioned perpendicular to the upper abdominal wall. For color Doppler studies, the velocity range was set at $13 \mathrm{~cm} / \mathrm{s}$. The IVC just below the diaphragm was set as the target, and the extent of reflux accompanying each heart beat was classified into the following four grades: no reflux (grade 0 , Figure 1), reflux extending for less than $1 \mathrm{~cm}$ below the diaphragm (grade 1), reflux extending for less than $3 \mathrm{~cm}$ (grade 2, Figure 2), and reflux of $3 \mathrm{~cm}$ or more (grade 3 ,

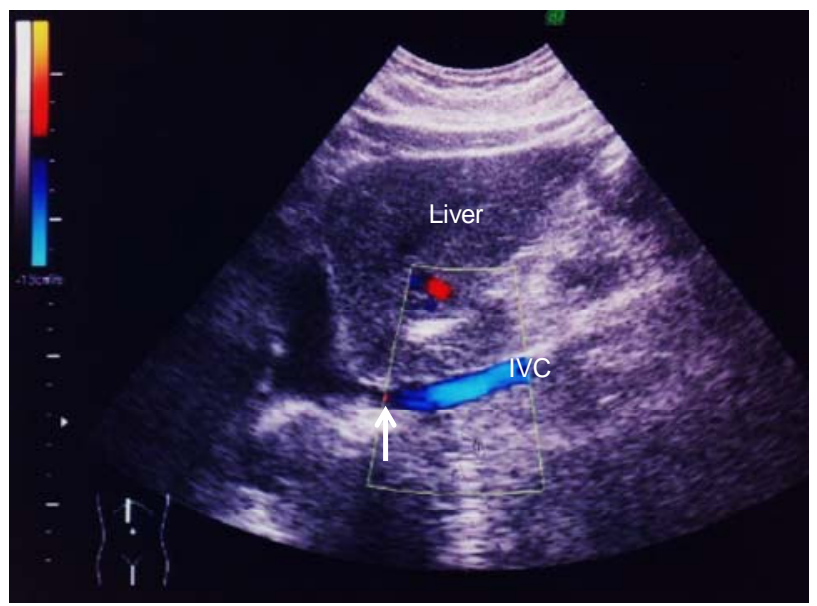

Figure 1. Transabdominal color Doppler ultrasonogram of the inferior vena cava (IVC) below the diaphragm (arrow) in a patient without IVC reflux (grade 0). Blue indicates forward blood flow in the IVC.

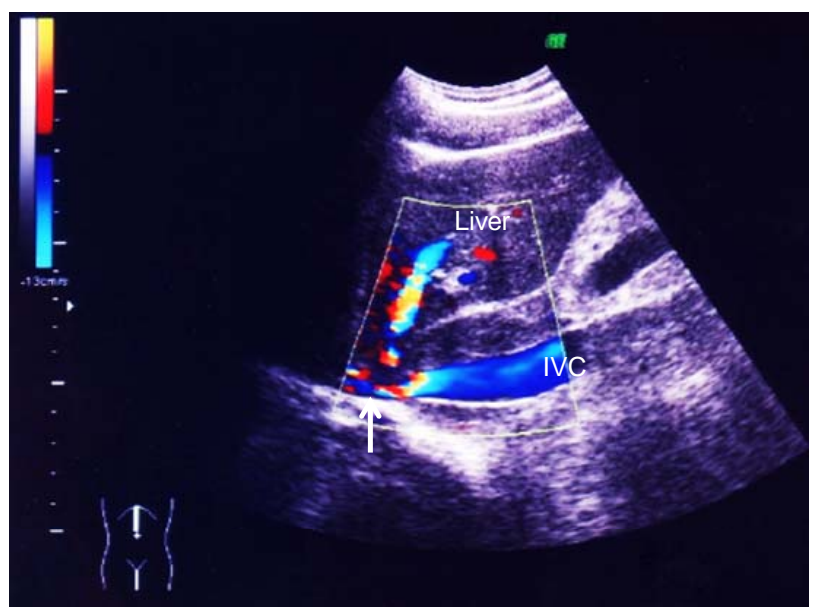

Figure 2. Transabdominal color Doppler ultrasonogram of the inferior vena cava (IVC) below the diaphragm (arrow) in a patient with IVC reflux (grade $2: 3 \mathrm{~cm}>$ reflux $\geq 1 \mathrm{~cm}$ ). Blue indicates forward blood flow in the IVC, while red and yellow show regurgitant flow.
Figure 3). The diaphragm was considered to correspond to the narrowest part of the IVC as it passed through the liver. Classification of the grade of reflux was performed in end expiration. When good images of the IVC were not obtained because of obesity or obscuration by the gastric contents, the patient was excluded from this study. Patients were excluded if they had any diseases that could cause hematuria, such as nephritis (proteinuriadominant), renal failure, renal tumor, urinary tract cancer, urinary stones, and urinary tract infection (white blood cell $>5 /$ high power field on urinalysis). Patients who had symptomatic or gross hematuria were also excluded. Therefore, only patients with asymptomatic microscopic hematuria or without hematuria were enrolled. Asymptomatic hematuria was detected by urinalysis and was classified into the following five grades: no occult blood (score 0$)$, occult blood \pm (score 0.5$)$, occult blood $1+$ (score 1), occult blood 2+ (score 2), and occult blood $3+$ (score 3 ). When urinalysis was performed several times, the average score was calculated. A total of 171 subjects (98 males and 73 females), in whom the presence and extent of IVC reflux could be assessed, were enrolled in this study. They were aged from 16 to 90 years old.

Results are reported as the mean \pm standard deviation. Student's $t$-test and the chi-square test were used for statistical analysis, and $p<0.05$ was considered to indicate statistical significance.

\section{Results}

Among the 98 males $(57 \pm 19$ years old $)$ in whom IVC reflux was evaluated, 50 had no detectable IVC reflux $(51 \%, 59 \pm 19$ years old) and 48 showed IVC reflux (49\%, $56 \pm 18$ years old). Among the 73 females $(61 \pm$ 16 years old) who were evaluated, 24 were without IVC

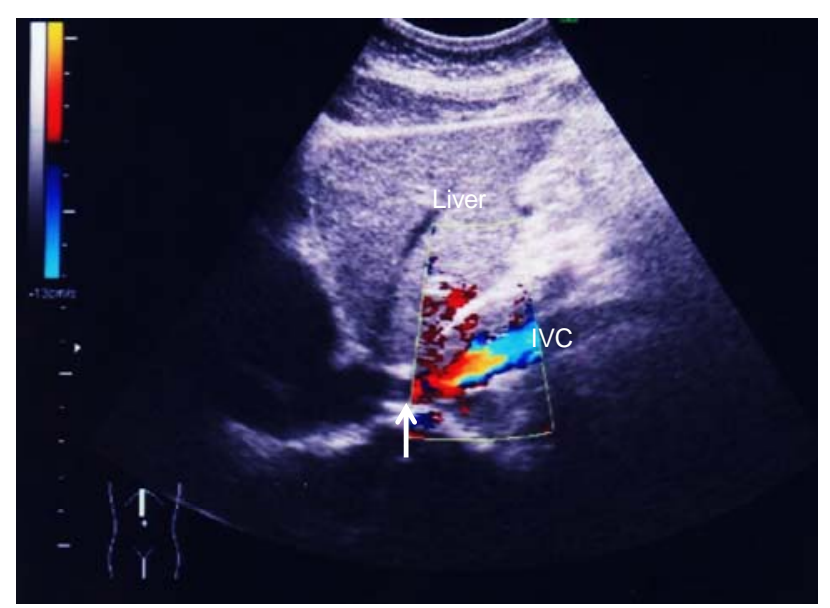

Figure 3. Transabdominal color Doppler ultrasonogram of the inferior vena cava (IVC) below the diaphragm (arrow) in a patient with IVC reflux (grade 3: reflux $\geq 3 \mathrm{~cm}$ ). Blue indicates forward blood flow in the IVC, while red and yellow show regurgitant flow. 
reflux $(33 \%, 61 \pm 18$ years old) and 49 had IVC reflux $(67 \%, 61 \pm 15$ years old $)$. The prevalence of IVC reflux was significantly $(p=0.0001)$ higher in females than males. In both sexes, there was no relationship between the detection of IVC reflux and age.

Hematuria was not detected in $45(90 \%)$ of the 50 males without IVC reflux, 17 (71\%) of the 24 males with grade 1 IVC reflux, $11(92 \%)$ of the 12 males with grade 2 reflux, and $8(67 \%)$ of the 12 males with grade 3 reflux (Table 1). There was a significant relationship ( $\mathrm{p}=$ 0.0499 ) between the existence of IVC reflux (grade 0 versus grades $1-3$ ) and hematuria (negative $(-)$ versus positive $( \pm, 1+, 2+$, and $3+)$ urine occult blood). The average hematuria score was 0.11 in male subjects without IVC reflux, 0.33 in those with grade 1 IVC reflux, 0.04 in those with grade 2 reflux, and 0.46 in those with grade 3 reflux. Therefore, a higher grade of IVC reflux was associated with an increase in the prevalence and severity of hematuria, except for grade 2 IVC reflux.

Among females, there was no hematuria in 15 (63\%) of 24 subjects without IVC reflux, $11(55 \%)$ of 20 subjects with grade 1 IVC reflux, $8(53 \%)$ of 15 subjects with grade 2 reflux, and $7(50 \%)$ of 14 subjects with grade 3 reflux (Table 2). However, there was no significant relationship between IVC reflux (grade 0 versus grades $1-3$ ) and hematuria (negative $(-)$ versus positive $( \pm, 1+, 2+$, and $3+)$ urine occult blood). The average hematuria score was 0.40 in female subjects without IVC reflux, 0.45 in those with grade 1 IVC reflux, 0.50 in those with grade 2 reflux, and 0.89 in those with grade 3

Table 1. Relationship between hematuria and inferior vena cava (IVC) reflux in 98 males.

\begin{tabular}{cccccccc}
\hline \multirow{2}{*}{$\begin{array}{c}\text { Grade } \\
\text { of IVC } \\
\text { reflux }\end{array}$} & No. of & \multicolumn{5}{c}{ Urine occult blood reaction } \\
\cline { 3 - 8 } & $(-)_{=0 \mathrm{p}}$ & $( \pm)_{=0.5 \mathrm{p}}$ & $(1+)_{=1 \mathrm{p}}$ & $(2+)_{=2 \mathrm{p}}$ & $(3+)_{=3 \mathrm{p}}$ & $\begin{array}{c}\text { Mean } \\
\text { points }\end{array}$ \\
\hline $\mathrm{G} 0$ & $50(51 \%)$ & 45 & 1 & 3 & 1 & 0 & 0.11 \\
$\mathrm{G} 1$ & $24(24 \%)$ & 17 & 2 & 4 & 0 & 1 & 0.33 \\
G2 & $12(12 \%)$ & 11 & 1 & 0 & 0 & 0 & 0.04 \\
$\mathrm{G} 3$ & $12(12 \%)$ & 8 & 1 & 1 & 2 & 0 & 0.46 \\
\hline
\end{tabular}

(No.: number, p: points, G: grade).

Table 2. Relationship between hematuria and inferior vena cava (IVC) reflux in 73 females.

\begin{tabular}{cccccccc}
\hline \multirow{2}{*}{$\begin{array}{c}\text { Grade } \\
\text { of IVC } \\
\text { reflux }\end{array}$} & $\begin{array}{c}\text { No. of } \\
\text { cases }\end{array}$ & \multicolumn{5}{c}{ Urine occult blood reaction } \\
\cline { 3 - 8 } G0 & $24(33 \%)$ & 15 & 1 & 7 & 1 & 0 & 0.40 \\
G1 & $20(27 \%)$ & 11 & 2 & 6 & 1 & 0 & 0.45 \\
G2 & $15(21 \%)$ & 8 & 3 & 2 & 2 & 0 & 0.50 \\
G3 & $14(19 \%)$ & 7 & 1 & 2 & 2 & 2 & 0.89 \\
\hline
\end{tabular}

(No.: number, p: points, G: grade). reflux. Therefore, a higher grade of IVC reflux was associated with an increase in the prevalence and severity of hematuria.

When the male and female subjects were combined, there was no hematuria in $60(81 \%)$ of the 74 subjects without IVC reflux, 28 (64\%) of 44 subjects with grade 1 IVC reflux, $19(70 \%)$ of 27 subjects with grade 2 reflux, and $15(58 \%)$ of 26 subjects with grade 3 reflux. There was a significant $(\mathrm{p}=0.0139)$ relationship between IVC reflux (grade 0 versus grades 1 - 3) and hematuria (negative $(-)$ versus positive $( \pm, 1+, 2+$, and $3+$ ) urine occult blood).

\section{Discussion}

This study showed that the existence of IVC reflux was not related to age, but its prevalence was significantly higher in females than males. A higher grade of IVC reflux was associated with an increased prevalence of asymptomatic microscopic hematuria and with more severe hematuria in both males and females. These findings suggest that IVC reflux may be one of the causes of asymptomatic microscopic hematuria.

Our previous study showed that chronic prostatitis in males and stress incontinence in females were significantly related to the existence of IVC reflux, suggesting that pelvic congestion due to IVC reflux caused by tricuspid regurgitation was associated with these diseases [12]. It is known that left renal congestion due to the nutcracker phenomenon (compression of the left renal vein between the abdominal aorta and the superior mesenteric artery) induces hematuria [2]. The nutcracker phenomenon can also induce the pelvic congestion syndrome [3], and pelvic congestion itself may promote bleeding from the urinary tract. In the present study, IVC reflux only extended a few centimeters past the diaphragm in the supine position, but reflux would become more prominent in the sitting or standing positions and could induce renal and/or urinary tract congestion. Therefore, IVC reflux due to tricuspid regurgitation may produce renal and/or urinary tract congestion that induces hematuria.

Hematuria is found more frequently in females than males when mass screening is performed. In our previous study [12] and the present study, the prevalence of IVC reflux was higher among females than males. Therefore, IVC reflux due to tricuspid regurgitation may particularly cause hematuria in females. Small renal or urothelial tumors, hemangiomas, and IgA nephropathy can also induce hematuria. Therefore, when the cause of microscopic hematuria is not identified by ultrasonography of the urinary tract, urine cytology, urinalysis (including the identification of dysmorphic red blood cells), and measurement of serum creatinine, $\operatorname{IgA}, \operatorname{IgG}, \mathrm{C} 3, \mathrm{C} 4$, and CH50 [13], the detection of IVC reflux or tricuspid re- 
gurgitation may be useful for diagnosis and/or follow-up of hematuria.

Although tricuspid regurgitation causes IVC reflux, surgical treatment of regurgitation is not considered unless liver dysfunction develops due to hepatic congestion. If renal and/or pelvic congestion occurs in humans, prolonged standing or prolonged sitting may exacerbate it, while adopting a supine position could improve it. In patients with venous congestion, the blood volume should be reduced. We have found that Gosha-jinki-gan [14], a Chinese herbal medicine, improves the symptoms of chronic prostatitis, and that Chorei-to (another Chinese herbal medicine) improves the symptoms of urethral syndrome [15]. These herbal medicines have a strong diuretic effect as well as anti-inflammatory activity. Therefore, it is possible that the diuretic effect of these herbal preparations improves the symptoms of diseases associated with pelvic congestion and hematuria.

\section{Conclusion}

Detection of IVC reflux by transabdominal color Doppler ultrasonography is more frequent in patients with microscopic hematuria, as is the case for those with chronic prostatitis or stress incontinence [12]. IVC reflux may induce renal or urinary tract congestion, and renal/urinary tract congestion secondary to IVC reflux may contribute to the occurrence of microscopic hematuria. When IVC reflux is detected in patients who have symptoms such as gross hematuria, chronic prostatitis, stress incontinence or pelvic congestion syndrome, lifestyle modification should be recommended such as avoidance of excessive water intake [16] and avoidance of standing or sitting for long periods.

\section{REFERENCES}

[1] D. Russo, R. Minutolo, V. Iaccarino, M. Andreucci, A. Capuano and F. A. Savino, "Gross Hematuria of Uncommon Origin: The Nutcracker Syndrome," American Journal of Kidney Diseases, Vol. 32, No. 3, 1998, p. E3. http://dx.doi.org/10.1053/ajkd.1998.v32.pm10074588

[2] A. de Schepper, "Nutcracker Phenomenon of the Renal Vein and Venous Pathology of the Left Kidney," Journal Belge de Radiologie, Vol. 55, No. 5, 1972, pp. 507-511.

[3] T. Scholbach, "From the Nutcracker-Phenomenon of the Left Renal Vein to the Midline Congestion Syndrome as a Cause of Migraine, Headache, Back and Abdominal Pain and Functional Disorders of Pelvic Organs," Medical Hypotheses, Vol. 68, No. 6, 2007, pp. 1318-1327. http://dx.doi.org/10.1016/j.mehy.2006.10.040

[4] J. T. Hobbs, "Varicose Vein Arising from the Pelvis Due to Ovarian Vein Incompetence," International Journal of Clinical Practice, Vol. 59, No. 10, 2005, pp. 1195-1203. http://dx.doi.org/10.1111/j.1368-5031.2005.00631.x

[5] A. D. Liddle and A. H. Davies, "Pelvic Congestion Syn- drome: Chronic Pelvic Pain Caused by Ovarian and Internal Iliac Varices," Phlebology, Vol. 22, No. 3, 2007, pp. 100-104. http://dx.doi.org/10.1258/026835507780807248

[6] A. Ganeshan, S. Upponi, L. Q. Hon, M. C. Uthappa, D. R. Warakaulle and R. Uberoi, "Chronic Pelvic Pain Due to Pelvic Congestion Syndrome: The Role of Diagnostic and Interventional Radiology," Cardio Vascular and Interventional Radiology, Vol. 30, No. 6, 2007, pp. 1105-1111. http://dx.doi.org/10.1007/s00270-007-9160-0

[7] G. Asciutto, A. Mumme, B. Marpe, O. Köster, K. C. Asciutto and B. Geier. "MR Venography in the Detection of Pelvic Venous Congestion," European Journal of Vascular and Endovascular Surgery, Vol. 36, No. 4, 2008, pp. 491-496. http://dx.doi.org/10.1016/j.ejvs.2008.06.024

[8] K. Sugaya, M. Miyazato, Y. Koyama, T. Hatano and Y. Ogawa, "Pelvic Congestion Syndrome Caused by Inferior Vena Cava Reflux," International Journal of Urology, Vol. 7, No. 4, 2000, pp. 157-159. http://dx.doi.org/10.1046/j.1442-2042.2000.00157.x

[9] K. Masuda, T. Sekine, H. Toide, T. Doi and E. Toda, "Points of Diagnosis of Valve Diseases," Japanese Journal of Medical Ultrasound Technology, Vol. 26, 2001, pp. 101-134.

[10] C. Y. Choong, V. M. Abascal, J. Weyman, R. A. Levine, F. Gentile, J. D. Thomas and A. E. Weyman, "Prevalence of Valvular Regurgitation by Doppler Echocardiography in Patients with Structurally Normal Hearts by Two-Dimensional Echocardiography," American Heart Journal, Vol. 117, No. 3, 1989, pp. 636-642.

http://dx.doi.org/10.1016/0002-8703(89)90739-4

[11] C. J. Lavie, K. Hebert and M. Cassidy, "Prevalence and Severity of Doppler-Detected Valvular Regurgitation and Estimation of Right-Sided Cardiac Pressure in Patients with Normal Two-Dimensional Echocardiograms," Chest, Vol. 103, No. 1, 1993, pp. 226-231. http://dx.doi.org/10.1378/chest.103.1.226

[12] K. Sugaya, E. Matsumura, S. Tasaki, R. Kimura, A. Kiyuna, S. Nishijima and K. Kadekawa, "Relationship between Urological Disease and Inferior Vena Cava Reflux on Color Doppler Ultrasonography," LUTS, Vol. 3, 2011, pp. 94-98.

[13] G. D. Grossfeld, M. S. Litwin, J. S. Wolf Jr., H. Hricak, C. L. Shuler, D. C. Agerter and P. R. Carroll, "Evaluation of Asymptomatic Microscopic Hematuria in Adults: The American Urological Association Best Practice PolicyPart II: Patient Evaluation, Cytology, Voided Markers, Imaging, Cystoscopy, Nephrology Evaluation, and Follow-Up," Urology, Vol. 57, No. 4, 2001, pp. 604-610. http://dx.doi.org/10.1016/S0090-4295(01)00920-7

[14] S. Nishijima, K. Sugaya, M. Miyazato and Y. Ogawa, "Effect of Gosha-Jinki-Gan, a Blended Herbal Medicine, on Bladder Activity in Rats," Journal of Urology, Vol. 177, No. 2, 2007, pp. 762-765. http://dx.doi.org/10.1016/j.juro.2006.09.077

[15] K. Sugaya, O. Nishizawa, H. Noto, K. Sato, K. Sato, N. Shimoda, R. Otomo and S. Tsuchida, "Effects of Tsumura Chorei-to and Tsumura Chorei-to-Go-Shimotsu-to on Patients with Urethral Syndrome," Hinyokika Kiyo, Vol. 38, No. 6, 1992, pp. 731-735. 
[16] K. Sugaya, S. Nishijima, M. Oda, M. Miyazato and Y. Ogawa, "Change of Blood Viscosity and Urinary Frequency by High Water Intake," International Journal of
Urology, Vol. 14, No. 5, 2007, pp. 470-472.

http://dx.doi.org/10.1111/j.1442-2042.2006.01734.x 